\title{
Arquivos pessoais, disponibilização e acesso na web: o caso do CPDOC
}

\section{Renan Castro ${ }^{1}$}

\section{RESUMO}

O presente artigo trata das questões de acesso ao acervo custodiado pelo Centro de Pesquisa e Documentação de História Contemporânea do Brasil, abordando suas políticas de preservação e disseminação digital. Apresenta impactos que essas políticas impõem às novas realidades de consulta e explora como esse cenário altera as rotinas de busca, acesso e consulta ao acervo. Percebe, portanto, que a utilização das tecnologias da informação e comunicação devem estar aliadas à nova realidade de demanda pelos acervos e sua preservação. Assim o objetivo deste artigo é compartilhar conhecimento sobre as formas de interação dos usuários do acervo do Centro de Pesquisa e Documentação de História Contemporânea do Brasil (CPDOC/FGV)com os recursos informacionais de pesquisa disponibilizados pela instituição.

Palavras-chave: Arquivos pessoais. Digitalização de documentos. Acesso digital.

\section{ABSTRACT}

This paper deals with the issues of access to the Centro de Pesquisa e Documentação de História Contemporânea do Brasil's collection, addressing their conservation policies and digital dissemination. It presents impacts that these policies impose the new realities of consultation and explores how this scenario changes the search routines, access and consultation of this collection. It perceives the use of information and communication technologies must be combined with the new reality of demand for collections. So the purpose of this article is to share knowledge about the forms of interaction of the users of the collecti on of the CPDOC/FGV with information resources research made available by the institution.

Keywords: Personal papers. Digitization. Digital access

\section{HISTÓRICO}

\footnotetext{
${ }^{1}$ Doutorando em Ciência da Informação pelo Programa de Pós-Graduação em Ciência da Informação do Instituto Brasileiro de Informação em Ciência e Tecnologia (IBICT) em convênio com Escola de Comunicação (ECO) da Universidade Federal do Rio de Janeiro (UFRJ). Mestre em Bens Culturais e Projetos Sociais pelo Programa de História, Política e Bens Culturais da Fundação Getulio Vargas - FGV (2011). Possui graduação em Biblioteconomia e Documentação pela Universidade Federal Fluminense (2006). É Bibliotecário do Centro de Pesquisa e Documentação de História Contemporânea do Brasil (CPDOC/ FGV), responsável pela organização do acervo de impressos dos a rquivos pessoais custodiados pela instituição.
} 
O Centro de Pesquisa e Documentação de História Contemporânea do Brasil (CPDOC) da Fundação Getúlio Vargas foi criado em 1973 com o objetivo de abrigar conjuntos documentais relevantes para a história recente do país e desenvolver pesquisas históricas, tendo inicialmente seu próprio acervo como fonte privilegiada de consulta. Os conjuntos documentais doados ao CPDOC, que podem ser conhecidos na íntegra através da internet, constituem, atualmente, a mais importante coleção de arquivos pessoais de homense mulheres com destacada atuação na vida pública contemporânea brasileira. A organização desses arquivos e sua abertura à consulta pública, hoje totalmente informatizada por meio do sistema Accessus, são tarefas primordiais do Centro.

O CPDOC atuou de maneira pioneira no Brasil na preservação e organização de arquivos privados de cunho pessoal. No início da década de 70 eram raras as instituições do gênero e, as metodologias de trabalho da área arquivística no país não eram muito legitimadas. Foi nesse contexto que o CPDOC iniciou discussões visando à elaboração e sistematização de uma metodologia para o tratamento da documentação arquivística que recebera, assim como um trabal ho de favorecimento de acesso às informações de seu acervo. (Braga, 2002, p.2).

Para Camargo (2003), foi também neste contexto, que a demanda por fontes de documentação no Brasil assumiu uma tendência de institucionalização como alternativa capaz de atender às então novas demandas sociais por informação especializada, sobretudo acadêmica. A autora atrela essa nova tendência de demanda informacional ao desenvol vimento dos centros de pesquisa e documentação que surgem pelo país a partir da década de 70 . Para ela, essa década registrou ações sistemáticas no sentido de proteção e organização do patrimônio documental que revelaram um intenso movimento em torno da questão cultural e da memória nacional. Assim, a década de 70 é o momento em que convergem tanto as demandas por fontes de pesquisa quanto o anseio acadêmico de investir no estudo da história recente do país, e a criação dos arquivos, que de certa forma, se apresenta como expressão dessa demanda por sua vocação de fomento às pesquisas acadêmicas.

A partir da constituição do CPDOC, com a doação do arquivo do ex-presidente Getúlio Vargas, seguido de arquivos de integrantes de seu governo como Oswaldo Aranha, Gustavo Capanema e de outros, teve início o trabalho de organização dessa documentação. Ao longo de sua história, grande parte dos esforços desenvolvidos pelo Centro teve como foco a organização e disponibilização do acervo sob sua custódia, atividade que, desde os primeiros tempos, está sob a responsabilidade do então Setor de Documentação. 
O então Setor de Documentação, atualmente Coordenação de Documentação, congrega as atividades e serviços que dizem respeito ao acervo histórico depositado no CPDOC. Atualmente é constituído pelo Programa de Arquivos Pessoais (PAP), responsável pelo tratamento e divulgação dos arquivos doados ao Centro, e pelo Programa de História Oral (PHO), responsável pelo controle e divulgação das entrevistas realizadas pelos pesquisadores da instituição. É no âmbito da Coordenação de Documentação que são discutidas questões relativas à preservação e ao acesso a essas diferentes fontes de pesquisa, bem como são desenvolvidos projetos que envolvem o tratamento e a referenciação dos acervos arquivísticos e do acervo de entrevistas.

A organização dos primeiros arquivos recebidos pela instituição tinha como objetivo a disponibilização da informação para um público amplo de pesquisadores, que se dava até então, exclusivamente através dos inventários analíticos. O inventário era o principal instrumento de pesquisa elaborado para a consul ta aos documentos textuais antes da informatização do acervo e possibilitava a pesquisa ao fornecer uma de scrição do conteúdo das unidades documentais integrantes de cada fundo ${ }^{2}$. Este instrumento obedecia a regras específicas, devendo seu produto final refletir de forma inequívoca o arranjo adotado na organização do arquivo. Consistia na descrição de cada uma das unidades documentais que integram as séries e subséries determinadas pelo arranjo. Além da descrição do conteúdo, cada inventário possuía, a título de apresentação, uma ficha técnica com informações gerais sobre o histórico do arquivo, a biografia do titular e a organização adotada.

Esses instrumentos de recuperação da informação forneciam apenas a referenciação do conteúdo de cada arquivo, apresentando resumos dos documentos (nos primeiros anos adotava-se a descrição individual dos documentos) ou dos dossiês que compunham o fundo arquivístico ${ }^{3}$. Ao manusear o inventário, o pesquisador entrava em contato com a totalidade do arquivo, devendo debruçar-se sobre ele para buscar os documentos úteis à sua pesquisa. $\mathrm{A}$ recuperação imediata de um assunto ou de um documento era impossível, já que, nos primeiros tempos, não havia indexação das unidades documentais. Quem pesquisava tinha, portanto, duas alternativas: ler página por página do inventário ou buscar informações com alguém que

\footnotetext{
2 Unidade documental é unidade de descrição que pode ser compreendida pelo documento ou conjunto deles, que se tomam por base, independentemente de sua classificação, para elaboração de instrumentos de pesquisa. (CAMARGO, Ana Maria de Almeida; BELLOTTO, Heloísa Liberalli (coord.) Dicionário de terminologia arquivística. São Paulo: Associação dos Arquivistas Brasileiros - Núcleo Regional de São Paulo: Secretaria de Estado da Cultura, 1996)

${ }^{3}$ Unidade de arquivamento constituída de documentos relacionados entre si por assunto (ação, evento, pessoa, lugar, projeto). (ARQUIVO NACIONAL (Brasil). Dicionário brasileiro de terminologia arquivística. Rio de Janeiro: Arquivo Nacional, 2005)
} 
já tivesse alguma experiência de pesquisa naquele acervo. Para se recuperar a informação a partir dos inventários, era necessário, na maioria das vezes, ler os resumos das unidades documentais (documentos unitários ou dossiês) a fim de selecionar aqueles documentos que seriam trazidos à mesa do pesquisador para leitura.

Após o desenvolvimento de um conjunto de procedimentos metodológicos próprios, inspirados nos padrões arquivísticos para o tratamento técnico da documentação, o Centro se dedicou a expandir o acervo disponível à consulta, buscando organizar os arquivos novos que chegavam, e a prestar consultorias relativas à implantação de centros de documentação em outras instituições também detentoras de acervos de natureza privada. Com o passar dos anos, porém, especialmente na segunda metade da década de 90, o caminho cada vez mais incontestável para implantação de um sistema informatizado de recuperação de dados do acervo se fez sentir. $O$ objetivo era seguir a tendência geral de informatização de serviços voltados para a pesquisa - seja em bibliotecas seja em arquivos - visando à agilidade e à precisão na recuperação de informações por parte dos usuários.

Esse movimento foi sentido principalmente a partir da proliferação dos computadores e da internet. Com as buscas por informação ganhando cada vez mais rapidez e automatismo, a tecnologia passou a servista como ferramenta necessária e indispensável a qualquer instituição que quisesse prestar um serviço eficiente e diferenciado. Essa visão estimulou o desenvolvimento das bases de dados para instituições custodiadoras de acervos, e influenciou as decisões estratégicas de muitas instituições voltadas para a pesquisa. Quem tivesse condições técnicas e principalmente financeiras de implementar a até então inédita "realidade informática", deveria fazê-lo o quanto antes.

O CPDOC não podia ficar alheio a essa pressão e, para manter sua posição de vanguarda na área de acervos arquivísticos, teve que investir na implantação de um sist ema de buscas. $\mathrm{E}$ um acervo tão peculiar tinha que contar com um sistema informatizado capaz de corresponder às suas especificidades e à responsabilidade de disponibilização dessas informações, assumida pelo Centro desde a sua fundação. A informatização es tava sendo colocada como uma forma de responder às exigências de uma realidade em franca expansão no campo da Ciência da Informação.

\section{A INFORMATIZAÇÃO DA PESQUISA NO ACERVO DO CPDOC/FGV}

No ano 2000 foi ao ar a primeira versão da base de dados Accessus. A ferramenta de busca pretendia ser uma interface amigável e vantajosamente funcional para os usuários. A 
partir de sua implantação, o acesso à informação custodiada pelo Centro estava disponível na internet, abrindo uma gama de possibilidades de acesso. O conteúdo descritivo do acervo, até então restrito aos inventários dos arquivos, disponíveis apenas nas instalações do centro de pesquisa, ganhava a internet e passava a poder ser vasculhado por meio de várias "chaves de busca" por qualquer interessado neste acervo. O Accessus mudou essencialmente as possibilidades de consulta, tornando possível vasculhar todo o acervo a partir de um tema de pesquisa.

Diante de uma importante transformação, que implicava traduzir técnicas tradicionais de organização em formatos padronizados de recuperação de informações num sistema automatizado, o Centro optou por desenvolver sua própria ferramenta de busca ao conteúdo catal ogado no acervo. A alternativa de desenvolver um mecanismo próprio foi considerada mais apropriada, já que a Fundação Getulio Vargas possuía uma área de tecnologia da informação capaz de criar essa ferramenta em absoluta consonância com as demandas do então Setor de Documentação, que era quem definia essas demandas. (Braga, 2002). A maior conquista dessa parceria foi construir um software próprio e absolutamente conectado com as necessidades específicas do acervo do CPDOC.

Anteriormente ao sistema Accessus, as descrições das unidades documentais eram feitas em fichas; a partir de sua implantação, adotaram-se planilhas para contemplar todos os campos previstos pelo arranjo metodológico utilizado pela instituição. Também antes da informatização se fazia uso de remissivas entre unidades documentais quando o documentalista queria indicar ao usuário a existência de documentos correlatos em outra série ou subsérie do mesmo arquivo; com a base informatizada, o cruzamento de informações passou a depender da indexação dos assuntos. De fato, com o Accessus, os descritores ${ }^{4}$ passaram a ser vistos como capazes de substituir as remissivas, já que documentos ou dossiês que abordassem os mesmos assuntos deveriam ser indexados com os mesmos descritores. A utilização deste sistema impactou, portanto, o gerenciamento e a consulta ao acervo do CPDOC. Em termos bastante gerais, pode-se dizer que o sistema passou a "responder perguntas" dos usuários, recuperando as informações relativas a uma consulta temática pontual. No métodoanterior, cabia ao próprio pesquisador verificar a existência da informação desejada por meio da leitura das descrições das unidades documentais disponíveis nos inventários. Estes traziam todo conteúdo de um

\footnotetext{
${ }^{4}$ Segundo a ABNT 12676 descritor é o termo preferido para representar um conceito. Para a instituição este é o principal mecanismo utilizado para representar um assunto e, por conseguinte, ponto de acesso recuperado pela base de dados.
} 
determinado fundo, a partir daí a responsabilidade de localizar um item de interesse era do próprio usuário.

\section{O PROJETO DE PRESERVAÇÃO E DISSEMINAÇÃO DO ACERVO HISTÓRICO DO CENTRO DE PESQUISA E HISTÓRIA CONTEMPORÂNEA DO BRASIL (CPDOC/FGV)}

O projeto de preservação do acervo, através da digitalização dos suporte originais, se inicia com o acervo iconográfico ${ }^{5}$, que devido a fragilidade de seu suporte e a presença predominante de informação imagética, mereceu estar apto a tamanho investimento. Já em 2005 o CPDOC inaugurou a política de preservação e difusão através da digitalização de documentos de natureza arquivística com a disponibilização online e gratuita do arquivo Getúlio Vargas. A iniciativa marcava o início de uma nova fase na consulta pública aos acervos da instituição, ao mesmo tempo que celebrava a memória do ex-presidente 50 anos após sua morte.

Mas é no ano de 2008 que a instituição inicia seu maior investimento na preservação e difusão de seu acervo com a digitalização e disponibilização online de mais de 360 mil páginas de documentos pessoais de natureza arquivística, além de cerca de 30.000 fotografias, 350 discos, 65 películas cinematográficas, 388 fitas (entre fitas VHS, U-MATIC, rolo e cassete). Esse projeto teve o apoio do Banco Santander, que através da Lei Rouanet, patrocinou a realização dessa atividade.

Posteriormente, o centro seguiu e segue buscando parcerias e projetos de foment opara continuar viabilizando as iniciativas de digitalização e difusão do acervo do CPDOC. Como a digitalização implica em uma grande aplicação de recursos financeiros, a instituição apenas consegue colocar em prática essa política se fomentada por projetos e parcerias. Essa constatação leva a Coordenação de Documentação a se empenhar em projetos de financiamento e editais de fomento que levam à digitalização de fundos específicos ou de temáticas próprias que se enquadrem em eventuais editais.

\footnotetext{
${ }^{5}$ A digitalização de fotografias é uma prática adotada pelo CPDOC des de o início dos anos 2000, a partir da criação da base de dados Accessus. Ao longo de dez anos esta prática possibilitou o acesso online de nossas fotografias. $O$ grande esforço do projeto foi a digitalização de álbuns fotográficos. Até este momento, digitalizávamos somente as fotografias avulsas, mais fáceis de serem tratadas. (AMADO, Daniele; SPOHR, Martina. Preservação e Difusão do Acervo Histórico do CPDOC: desafios e perspectivas, $2012, \mathrm{~s} / \mathrm{n})$
} 
Mesmo com esse desafio de busca por recursos, atualmente o CPDOC conta com 15 fundos com sua tipologia textual/manuscrita digitalizada, somando aproximadamente 575.000 imagens disponíveis para consulta, num universode mais de 2,5 milhões de páginas disponíveis. ${ }^{6}$

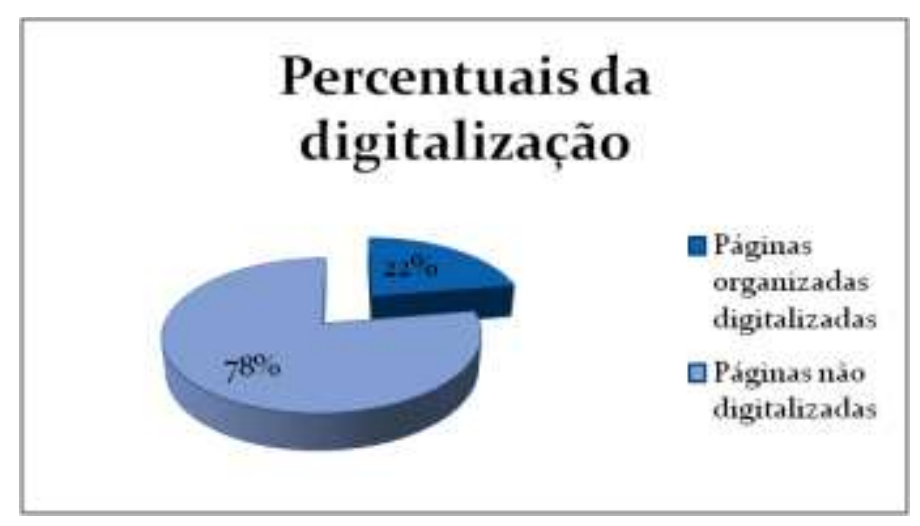

Além desses itens, todas as fotografias dos fundos disponíveis para consulta estão digitalizadas - aproximadamente 80.000 fotografias. Todo esse conteúdo está acessível online no portal CPDOC e totalmente gratuito para a sociedade brasileira e a comunidade acadêmica nacional e internacional.

\section{DIFUSÃO E ACESSO ÀS FONTES HISTÓRICAS: O IMPACTO DA DISPONIBILIZAÇÃO ONLINE DE DOCUMENTOS DO ACERVO CPDOC/FGV}

Podemos resumir em dois pontos principais as ações de difusão e acesso ao acervo da instituição. Essas ações são implementadas através da busca e acesso online ao acervo do CPDOC/FGV. Atualmente essas ações são concretizadas pela busca simples e pela disponibilização da versão digital dos documentos. A 'busca simples' funciona baseando sua varredura na estratégia de busca booleana calcada na localização de palavras iguais. ${ }^{7}$ Esse tipo de busca está baseado na mesma estratégia dos buscadores da internet, que varrem um conteúdo à procura de uma palavra idêntica. Essa novidade buscou atender à demanda por uma

\footnotetext{
${ }^{6}$ Apesar de estar vinculado à obtenção de recursos financeiros possibilitados por editais de fomento, a instituição segue comprometida na disseminação de seu acervo através da contínua digitalização dos fundos arquivísticos sob sua custódia.

${ }^{7}$ A busca booleana aqui mencionada considera a aplicação da Lógica de Boole a um tipo de sistema de recuperação da informação, no qual se combinam dois ou mais termos, relacionando-os por operadores lógicos, que tornam a busca mais restrita ou detalhada. As estratégias de busca são baseadas na combinação entre a palavra contida em determinados documentos e a correspondente questão de busca, elaborada pelo usuário do sistema.
} 
informação mais rápida e diversificada no acervo do CPDOC, compreendido não apenas pelos arquivos pessoais, mas também pelas entrevistas do Programa de História Oral e pelos seis mil verbetes que compõem o Dicionário Histórico-Biográfico Brasileiro. A ideia era permitir que o usuário consultasse a totalidade dos diferentes acervos sem ser obrigado a entrar nas diferentes bases de dados que recuperam as informações de cada tipo de acervo.

Enquanto que no Accessus a busca compreende apenas o acervo de arquivos pessoais, no recurso da 'busca simples' o usuário não fica restrito a uma única base de dados. Além disso, a 'busca simples', ao percorrer o universo das informações relativas aos arquivos, ou seja, ao percorrer o Accessus, varre os resumos que cada unidade documental possui. A diferença em relação à busca realizada no Accessus reside no fato de que o mecanismo de busca, ou seja, na busca tradicional, apenas há varredura nos descritores por meio dos quais os assuntos foram indexados e não nos resumos. Esse pode ser considerado um avanço, porque abre novos pontos de acesso às informações, mas essa medida pode determinar frustrações nas pesquisas dos usuários mais especializados, além do surgimento de outro modelo de consulente menos especial izado. Esse investimento em informatização criou um ambiente virtual propício para a pesquisa e consulta ao acervo do CPDOC. Essa política também foi responsável por tornar o acervo mais acessível a um público antes alheio a esse recurso informacional.

A projeção que a disseminação proporciona ao acervo pelo acesso web é comprovada quando analisamos um recorte de fundos mais consultados no período de 2012 a 2014. Verificamos na totalidade dos fundos organizados e disponíveis para pesquisa, que dos 10 fundos mais consultados 7 já estão disponibilizados para consulta pública no portal CPDOC.

A tabela a seguir ilustra essas características.

\begin{tabular}{|c|c|}
\hline \multicolumn{1}{|c|}{ Arquivo } \\
\hline 1 & Getúlio Vargas \\
\hline 2 & Gustavo Capanema \\
\hline 3 & Anísio Teixeira \\
\hline 4 & Oswaldo Aranha \\
\hline 5 & Ernesto Geisel \\
\hline 6 & João Goulart \\
\hline 7 & Alzira Vargas do Amaral Peixoto \\
\hline 8 & Ernâni do Amaral Peixoto \\
\hline 9 & Ulysses Guimarães \\
\hline 10 & Antônio Azeredo da Silveira \\
\hline
\end{tabular}

Tabela apresenta os 10 arquivos mais consultados no período 2012-2014 
A ilustração a seguir comprova que a digitalização do acervo projeta fortemente a consulta aos mesmos. Como a digitalização e a consecutiva liberação à consulta online se dão por fundos arquivísticos, nos é possível observar esse movimento com precisão. No exemplo abaixo, vemos que o arquivo Ernesto Geisel, devido à relevância histórica de seu titular, sempre desfrutou de grande demanda por seu conteúdo. Mesmo assim a digitalização foi capaz de torná-lo ainda mais acessado, levando-o à segunda posição ante a quarta colocação no ano anterior ao de sua disponibilização online. Outros exemplos ainda são mais surpreendentes, como no caso acervo Juarez Távora. Esse acervo ocupava a 29o posição de consulta e, após sua liberação na rede, passou a ocupar a 10 colocação entre os mais consultados. A tabela a seguir exibe outros exemplos da potencialização dada pela liberação das cópias digitais na web dos acervos do CPDOC.

\begin{tabular}{|c|c|c|}
\hline Arquivo & $\begin{array}{l}\text { Antes da } \\
\text { digitalizaçâo }\end{array}$ & $\begin{array}{l}\text { Depois da } \\
\text { digitalizaçâo }\end{array}$ \\
\hline Ernesto Geisel & $4^{\circ}(\mathrm{em} \mathrm{2007)}$ & $2^{\circ}(\mathrm{em} \mathrm{2008)}$ \\
\hline Juarez Túvora & $29^{\circ}(\mathrm{em} \mathrm{2008)}$ & $10^{\circ}(\mathrm{em} 2009)$ \\
\hline Paulo Nogueira Batista & $33^{\circ}$ (em 2009) & $19^{\circ}(\mathrm{em} \mathrm{2012})$ \\
\hline Antônio Azeredo da Silveira & $16^{\circ}(\mathrm{em} \mathrm{2009)}$ & $8^{\circ}(\mathrm{em} \mathrm{2012)}$ \\
\hline Cafe Filho & $28^{\circ}(\mathrm{em} \mathrm{2013)}$ & $11^{\circ}(\mathrm{em} \mathrm{2014})$ \\
\hline Clemente Mariani & $20^{\circ}(\mathrm{em} \mathrm{2013)}$ & $15^{\circ}(\mathrm{em} \mathrm{2014})$ \\
\hline
\end{tabular}

Volume de consulta ocupada pelos fundos antes e depois da digitalização de cada um deles

Todo esse aparato tecnológico oferecido pelo CPDOC/FGV aos seus usuários acaba por impulsionar para o ambiente virtual as demandas pelos serviços oferecidos como a reprodução de documentos, por exemplo. Se realizarmos uma comparação entre as solicitações de reprodução de documentos ${ }^{8}$ notaremos que mais de 93\% em 2011; 98\% em 2012; 77\% em 2013 e 78\% em 2014 desse tipo de demanda foi realizada a partir do ambientevirtual, ou seja, através do portal CPDOC sem nenhum tipo de contato presencial.

\footnotetext{
${ }^{8}$ Consideramos nesta análise a penas as solicitações por algum serviço oferecido pela instituição como a reprodução de documentos e/ou de iconografia, etc. O número que nos esclarecea totalidadeda busca por termos de pesquisas chegou a mais de 116 mil termos pesquisados. Convém registrar também que 5847 novos usuários se cadastraram para acessar os serviços da instituição em 2014.
} 
Finalizando nossa observação, atestamos que a disponibilização na web de documentos digitalizados do acervo do CPDOC/FGV é crucial para impulsionar a consulta aos arquivos. Dessa forma, a maior parcela da consulta diante a totalidade do acervo correspondente aos documentos disponibilizados digitalmente é de $57 \%$. Ou seja, mesmo possuindo apenas de $22 \%$ do acervo digitalizado, a consulta a esse universo é de $57 \%$. Enquanto que os outros $78 \%$ não disponibilizados no portal CPDOC correspondem por apenas $43 \%$ da demanda de consulta diante a totalidade do acevo da instituição.

\section{Total da consulta aos arquivos (2012-2014)}

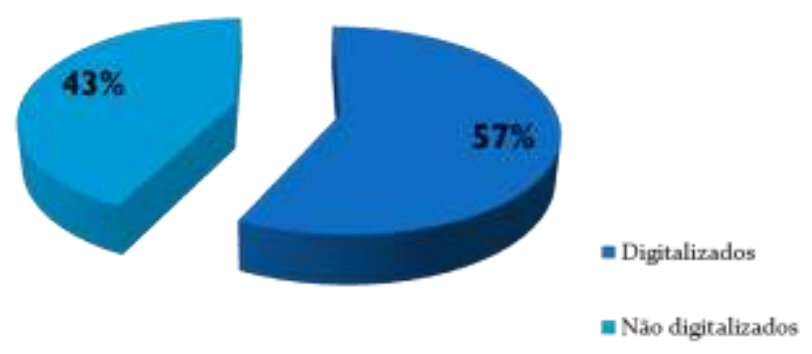

\section{NOVAS FERRAMENTAS DE INTEGRAÇÃO WEB}

Desde o início de 2016, o CPDOC coloca em prática a primeira iniciativa no sentido de simplificar a busca através da desobrigação de login para pesquisa no Accessus. Antes com a pesquisa condicionada ao login que exigia cadastro prévio, agora o usuário não encontra nenhum trâmite neste processo além de sua própria estratégia de busca. Com essa alteração, ao clicar na página de busca a pesquisa já estará acessívele, porisso, solucionou-se um eventual fator desmotivador para o acesso de determinado perfil de público.

No mesmo conjunto de inciativas, foi desenvolvida pela equipe de tecnologia da informação da FGV o recurso de url's únicas. Essa ação consistiu em conferir a cada item referenciado no Accessus um endereço de internet válido e exclusivo, possibilitando acesso direto ao item em questão. Dessa forma um usuário pode também local izar um resultado de um levantamento através de seu respectivo link. Essas url's amigáveis como também podemos chamá-las, passaram a permitir que, por exemplo, um determinado documento possa ser compartilhado nas redes sociais das quais o pesquisador faça parte. Como o ambiente online tem se configurado como um espaço indispensável de interação social e disseminação de informações, nada mais natural que o resultado de uma pesquisa ou documento relevante esteja passível de ser compartilhado virtualmente. 
A soma das duas iniciativas anteriores, combinando links individualizados para os documentos com a desobrigação de login prévio, permitiram que os metadados do Accessus tornassem harmonizáveis com os motores de busca da internet. Assim significa dizer que, num primeiro momento, ferramentas como Google poderão rastrear, armazenar e disponibilizar em sua busca dados dos documentos como resumo, cl assificação e até mesmo palavras-chave. Esse novo formato permitirá, guardando-se as devidas proporções, que a pesquisa possa ser feita dentro do próprio buscador web, levando o acesso aos documentos do CPDOC a um patamar sem precedentes. Essa mudança nos padrões de busca tornará o conteúdo dos arquivos históricos do CPDOC acessíveis a um público até então não imaginado, que por perfil não teria afinidade com pesquisas em arquivos. Além de tornar-se acessível a mais usuários potenciais, a liberação desse conteúdo na internet poderá contribuir para o próprio conteúdo da rede, se considerarmos a temática de abordagem do acervo do CPDOC. O que significa dizer que, futuramente, os buscadores poderão associar temáticas da história do Brasil com os resultados que apontem para o conjunto documental da instituição. Assim, o CPDOC proporcionará aos internautas da rede mundial de computadores conteúdos informacionais diferenciados, baseados em documentação histórica, elevando assim o patamar do conteúdo da informação oferecido na web.

Não obstante, a tendência atual da mobilidade, também vocaciona a instituição a inspirar-se por essa linha. Com as pessoas acessando crescentemente suas informações pessoais, serviços, entretenimento e até suas ferramentas de trabalho em dispositivos conectados à internet mesmo em movimento, fez-se necessário considerar tal orientação. Essa cultura que podemos classificar como sendo da conectividade móvel tem sido uma constante na sociedade atual. Prova desse movimento é que as informações antes acessadas nas telas de computadores, seguiram um movimento de migração para dispositivos portáteis como celulares e tablets. O simples ato de abrir um jornal na tela do computador pessoal fez-se inevitável a migração para as telas menores e, assim, possibilitar acessibilidade ao indivíduo a qualquer momento. Sem a imposição da imobilidade colocada pelos fios, o acesso a conteúdos informacionais se coloca à disposição dos internautas em qualquer momento e lugar.

Esse comportamento serviu de motivação para o CPDOC marcar presença também nessa tendência levando a instituição a tornar o conteúdo informacional do acervo disponível considerando também o conceito de mobilidade. Antenando-se aos novos tempos, foi implementada a construção do App CPDOC, ferramenta desenvolvida para funcionar em plataformas de smartphones e tablets, permite o acesso às bases de dados do CPDOC distante apenas do toque dos dedos. O aplicativo disponível nas lojas de conteúdo de sistemas operacionais móveis como Android e IOS, pode ser baixado gratuitamente. Funcionando dentro 
do App FGV, o aplicativo CPDOC fornece acesso inclusive aos documentos digitalizados disponíveis para consulta online. Tratando-se, portanto de uma versão portável das bases de dados da instituição.

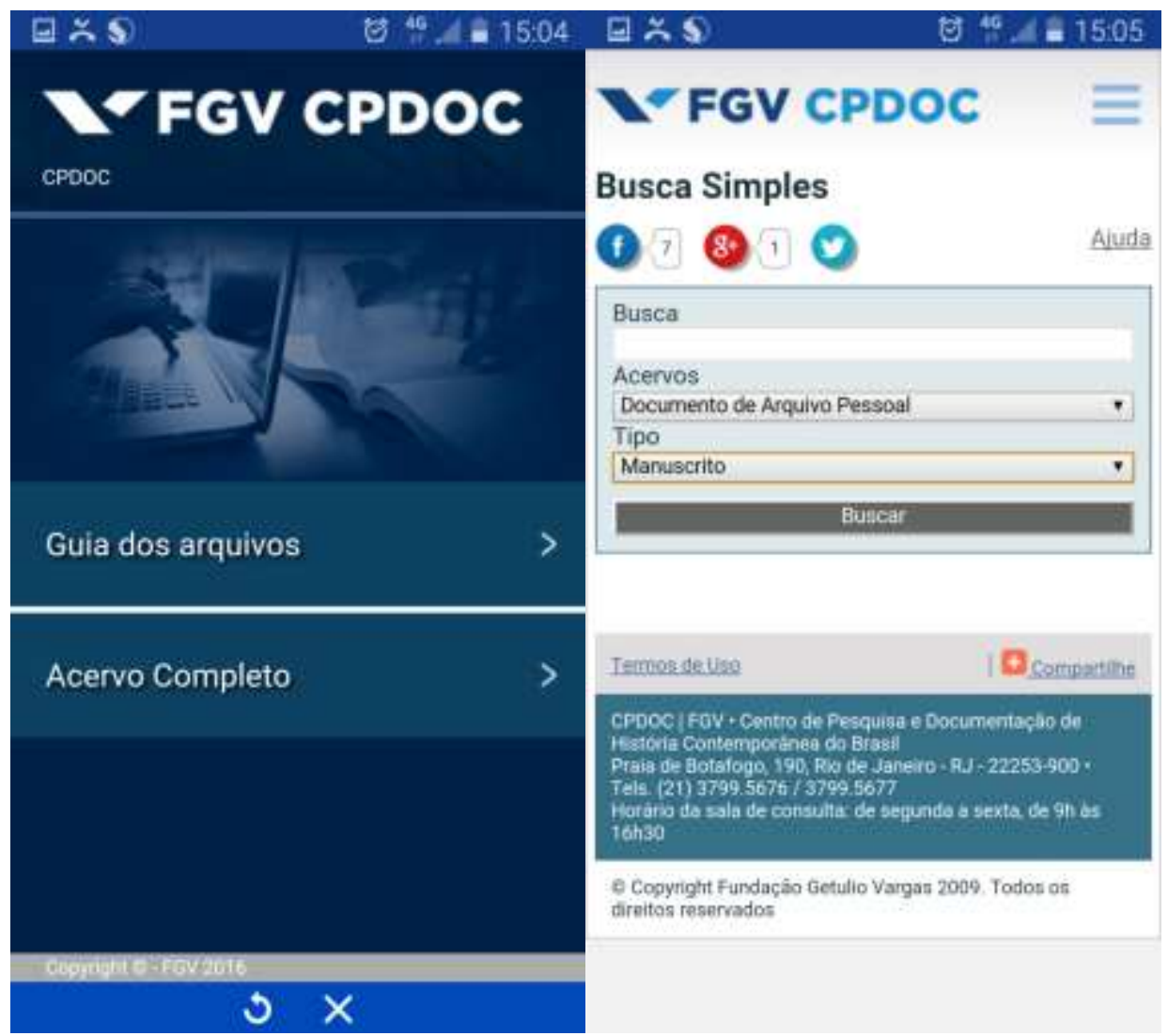

Reprodução da tela inicial do aplicativo de busca ao acervo do CPDOC

\section{CONSIDERAÇÕES FINAIS}

O projeto de preservação e difusão do acervo histórico do Centro de Pesquisa e História Contemporânea do Brasil (CPDOC/FGV) segue em expansão apesar das complexidades com as quais um projeto desse porte se depara. Apesar de dispendioso, a instituição segue na busca de parcerias e editais de fomento que possam viabilizar essas ações.

Em 10 anos o CPDOC digitalizou através de projetos de financiamento diversos os arquivos como Getúlio Vargas em 2005, Ernesto Geisel em 2007. Entre 2008-2009, dentro do projeto patrocinado pelo Banco Santander, através da Lei de incentivo a cultura, foram digitalizados cerca de 300.000 páginas de documentos de diversos arquivos. Além desses arquivos documentais, este projeto também possibilitou a digitalização de 5.000 horas de gravação de entrevistas de história oral. Atualmente, segue em vias de conclusão um projeto 
viabilizado pelo Ministério da Cultura para tornar disponíveis para consulta online o arquivo pessoal do ministro da Educação e Saúde (1934-1945), Gustavo Capanema, e dos presidentes da República - Wenceslau Brás (1910-1914), Eurico Gaspar Dutra (1946-1951) e João Café Filho (1954-1955). Nesse projeto a previsão é de um total de 350.000 imagens digitalizadas eleve para o patamar de $33 \%$ o nível de acervo digitalizado. Este projetotambém contempla a digitalização de documentos textuais, iconográficos, sonoros e audiovisuais do arquivo pessoal de André Franco Montoro, num total estimado em mais 70.000 páginas de documentos, 5.500 fotografias e 300 horas de gravação de imagens em movimento.

Com a disponibilização dos conteúdos documentais digitalizados na web, o CPDOC/FGV universaliza o acesso à informação para a sociedade, sobretudo no contexto brasileiro. Oferecendo um aparato documental desse porte na web num país com dimensões continentais de grandes desigualdades sociais e diferenças culturais, democratiza-se o conhecimento sobre a História do próprio país. Numa outra vertente, a utilização da digitalização na preservação dos suportes garante que esse acervo seja preservado para as futuras gerações sem implicar em cerceamento do acesso.

Com essas iniciativas o Centro de Pesquisa e Documentação da Fundação Getulio Vargas busca aperfeiçoar medidas de preservação de seu acervo histórico, ampliar o processo de universalização do acesso gratuito aos conteúdos histórico-culturais do país presentes nesse acervo e desenvolver produtos que potencializem sua difusão para um público cada vez mais amplo.

\section{REFERÊNCIAS}

AMADO, Daniele; SPOHR, Martina. Preservação e Difusão do Acervo Histórico do CPDOC: desafios e perspectivas, 2012, [s.n]

ARQUIVO NACIONAL (BRASIL). Dicionário brasileiro de terminologia arquivística. Rio de Janeiro: Arquivo Nacional, 2005

BRAGA, Suely. Accessus: sistema de documentação histórica do CPDOC, 2002 [s.n.]

CAMARGO, Célia. Centros de documentação e pesquisa histórica: uma trajetória de três décadas. In: CPDOC 30 anos/Textos de: Célia Camargo...[et al]. Rio de Janeiro: Ed. Fundação Getulio Vargas, 2003. p.21-44. 
CAMARGO, Ana Maria de Almeida; BELLOTTO, Heloísa Liberalli (coord.) Dicionário de terminologia arquivística. São Paulo: Associação dos Arquivistas Brasileiros - Núcleo Regional de São Paulo: Secretaria de Estado da Cultura, 1996

CASTRO, Renan Marinho de. A recuperação da informação sob a ótica dos usuários: um estudo de caso do uso da base dados Accessus. 2011. 122f Dissertação (Mestrado em Bens Culturais e Projetos Sociais) Fundação Getulio Vargas, Rio de Janeiro, 2011

CENTRO DE PESQUISA E DOCUMENTAÇÃO DE HISTÓRIA CONTEMPORÂNEA DO BRASIL. CPDOC 25 anos: relatório de atividades. Rio de Janeiro, 1998. 91p.il.

CPDOC 30 anos/ Textos de: Célia Camargo...[et al]. Rio de Janeiro: Ed. Fundação Getulio Vargas, 2003. 192p.

DICIONÁRIO BRASILEIRO DE TERMINOLOGIA ARQUIVÍSTICA. Rio de Janeiro: Arquivo Nacional, 2005.

FONSECA, Maria Odila; JARDIM, José Maria. Estudos de usuários em arquivos: em busca de um estado da arte. DataGramaZero: revista de Ciência da Informação, Brasília: IBICT, v.5, n.5, out.2004

GÓMEZ, Maria Nélida Gónzalez de. Novas fronteiras tecnológicas das ações de informação: questões e abordagens. Ciência da Informação, Brasília, v.33, n.1, p.55-67, jan./abr. 2004

GONÇALVES, Martina Sphor. Políticas de arranjo e descrição em arquivos privados pessoais: o caso do Cpdoc. 2007 [s.n.]

LIMA, Vânia Mara Alves. A informação documentária: codificação e decodificação. TransInformação, Campinas, 19(2):119-127, maio/ago., 2007

RONDINELLI, Rosely Curi. Gerenciamento Arquivístico de Documentos Eletrônicos: uma abordagem teórica da diplomática arquivística contemporânea. Rio de Janeiro: Editora FGV, 2005, $160 \mathrm{p}$. 